\title{
Nominal Stent Diameter
}

National Cancer Institute

\section{Source}

National Cancer Institute. Nominal Stent Diameter. NCI Thesaurus. Code C150189.

Deployed stent diameter, as marked on packaging. 